\title{
URDT
}

International Journal of Recent Development in Engineering and Technology

Website: www.ijrdet.com (ISSN 2347-6435 (Online)) Volume 10, Issue 1, June 2021)

Manuscript Received: 02 Feb 2021, Received in Revised Form: 18 May 2021, Accepted: 19 June 2021 DOI: 10.54380/IJRDETV10I108

\section{On the Question of Electro mobility Promotion}

\author{
Natallia Yankevich ${ }^{1}$, Stsiapan Yankevich ${ }^{2}$ \\ ${ }^{1,2}$ National Academy of Sciences of Belarus, 66, Independence av., Minsk, 220072, Belarus \\ ${ }^{1}$ lab_12@tut.by, ${ }^{2}$ stepan.yankevitch@yandex.by
}

\begin{abstract}
To create a competitive and resource-efficient transport system, the European Union transport policy provides by 2030 achieving almost zero carbon dioxide emissions of vehicles used in large urban centers, and gradually phasing out the use of vehicles using traditional fuels - by 2050. The large-scale and accelerated development of the principles of electric mobility in Europe can make a significant contribution to the realization of these goals, has a positive impact on the ecological friendliness of the environment, and can also improve the situation with employment in Europe. However, it is impossible to abandon immediately of piston power units, including diesel ones there are too many of them. Moreover, considering the size of the "carbon footprint" of cars, which means the totality of all the harmful emissions and greenhouse gases that an object produces during its life cycle, it is currently impossible to state unambiguously about the environmental superiority of electric vehicles compared to cars equipped with gasoline and diesel engines. Therefore, the development of approaches that can justify strategic directions, describing the principles of long-term operation of machines with various types of engines, is relevant.
\end{abstract}

Keywords - electromobility, equilibrium strategy, game theory.

\section{INTRODUCTION}

The prospect of banning cars with internal combustion engines, which used to seem fantastic, has become quite real over the past five years. Many experts and car manufacturers themselves note that now electric cars are the main driving force of the entire modern automotive industry. According to experts, we are on the verge of global changes: by 2030 about $40 \%$ of all new cars will be electric, and by 2050 their share is projected at $100 \%$.

Shortage of fuel and connected with it increasing of energy prices, as well as a worldwide understanding of the need to protect the environment, are causing more and more car manufacturers to look for an alternative to an internal combustion engine.

There is the "third era" of electric motors usage today. Electric cars gained popularity not only in connection with rising oil prices, but also due to global concern about environmental issues.
Previously, the topic of air pollution in major cities of the world was not so relevant, which is why electric cars are not widely used.

The discovery of rich oil fields, the relatively greater weight and much lower speed capabilities of electric vehicles compared to cars with internal combustion engines led to the actual cessation of electric vehicles production in 1930.

The revival of interest to the electric vehicles occurred in the 1960s due to environmental issues of motor vehicles and the prospect of oil depletion. However after 1982 interest in electric vehicles declined again due to the sharp changes in the oil market and inefficient performance indices of pilot batches, connected with the deficiencies of chemical energy sources.

A new stage in the development of electric vehicles began in the early 90 s of the XX century due to the tightening of legislation on environmental pollution. Electromobility received an additional incentive for widespread adoption due to the "dieselgate".

However, it is impossible to abandon piston power units, including diesel ones, at one minute - there are too many of them. Currently, $20 \%$ of passenger cars are equipped with diesel engines, $75 \%$ with gasoline and only the remaining $5 \%$ are electric cars, hybrids and gas-powered cars.

The situation with the introduction of COVID-19 quarantine measures in countries that are the largest manufacturers of automotive equipment, as well as a drop in oil prices and the associated reduction in gas prices, has added even more questions.

So understanding of the fact that the period of simultaneous operation of internal combustion engines, electric motors and their modifications can last quite a long time, leads to the need to develop methods and means that allow, if not control, but at least objectively influence the mentioned process.

In this case, it may be useful to apply the approaches of the game theory - the section of applied mathematics, using the methods of which scientists (primarily economists) are modeling the behavior of several objects, when each decision of a separate object depends on the decisions made by the others. 


\section{U \\ International Journal of Recent Development in Engineering and Technology \\ Website: www.ijrdet.com (ISSN 2347-6435 (Online)) Volume 10, Issue 1, June 2021) \\ Manuscript Received: 02 Feb 2021, Received in Revised Form: 18 May 2021, Accepted: 19 June 2021 DOI: 10.54380/IJRDETV10I108}

The mathematical theory of games is currently under active development. Its theoretical base is inherently very expensive, which is why it is used mainly only if the aims justify the means, namely in politics, the economy of monopolies and the distribution of market power, etc.

At the same time, the importance and relevance of the issue under consideration makes relevant the application of game theory to the development of a strategy for the operation of engines of various types.

\section{State-Of-Art Of The Electromobility Market}

Currently, the largest automakers are boosting the production of electric vehicles. For example, the Japanese manufacturer Toyota announced its intention by approximately 2025 to completely stop the production of cars with gasoline or diesel engines, leaving in its model line only hybrids, electric cars and cars running on hydrogen [1].

Volkswagen has launched a total of 70 new electric vehicles on the market during the next 10 years - against 50 , which was provided for by the previous version of Volkswagen's "electric" strategy. Accordingly, the total production of electric cars by this auto giant, according to the revised forecast, should increase from 15 to 22 million units by 2030 .

In the case of the implementation of this plan, electric cars will account for up to $40 \%$ of all Volkswagen Group sales by then. By 2025, a large-scale "electric" strategy will allow Volkswagen to reduce the average $\mathrm{CO}_{2}$ emissions by model line by $30 \%$ compared to 2015 . Until 2023, the concern will invest about 30 billion Euros in electrification [2].

Other major car companies are also betting on electricity. For example, Daimler recently decided to stop investing in the development of new internal combustion engines and focus on electrical technology and the development of batteries for electric cars.

Honda Motor Co Ltd has stated that by 2021 in Europe, all its diesel cars will be decommissioned in favor of models with electric power motors. The corresponding decision was made as part of a new strategy, according to which the Japanese automaker plans to electrify by 2025 all of its cars, supplied to European market. This plan, in turn, is part of its long-term goal, that by 2030 , electric vehicles make up two-thirds of all brand models [3].

Mitsubishi is actively introducing electricity into the lineup, so it's time to abandon the diesel engines on the ASX and Outlander.
The latter one has long been available in the hybrid version (PHEV), and the ASX is living out its last days at the assembly line. Porsche recently announced the discontinuation of diesel modifications (Macan and Panamera), and for the new Cayenne diesel was never introduced. But the German brand hybrids are selling excellent.

The number of cars that left the diesel mill included European compact cars Skoda Fabia and Opel Corsa, as well as the Seat Toledo sedan. It is interesting that Volvo, with its wide range of diesel engines in the current lineup, announced that after the launch of the V60, it stops developing heavy-fuel engines and focuses on improving hybrid and electric power plants.

Demand for diesel engines is rapidly declining largely due to the "Dieselgate". Although the scandal took place back in 2015, the real problems for manufacturers are only starting now - in just one year, the share of diesel cars fell to $36 \%$ in 2018, which is $8 \%$ less than in 2017 (and 19\% less for compared with 2011, when the peak of demand for diesel engines was recorded). Gasoline cars at the same time have $57 \%$ of the market $-7 \%$ better than last year.

Hybrids, the number of which is becoming more and more, also outperform the diesel engines in many cases. Almost all manufacturers now have such economical versions, their prices are quite reasonable, and fuel consumption is sometimes even less than that of diesel engines.

Electric cars and hybrids have seriously increased their share - from $4.8 \%$ to $6.1 \%$. For example, in Norway, such models generally occupy a third of the entire market. For comparison, 10 years ago, electric cars and hybrids accounted for only $0.5 \%$ of sales.

The most popular electric car in Europe is the Nissan Leaf (38.7 thousand cars). Renault ZOE (38.1 thousand cars) is at the second place, followed by the electric Volkswagen Golf (21.1 thousand), BMW i3 (18.1 thousand) and Tesla Model S (16.4 thousand).

Mitsubishi Outlander (23.1 thousand) is the leader among the plug-in hybrids, and Toyota Yaris (129 thousand) - among usual hybrids.

Despite the "Dieselgate", sales of cars in 2018 reached 15.6 million units. This is the best result since 2007, when 16.02 million cars were sold. Moreover, the result of 2007 could have been exceeded, however, in the fourth quarter, car sales fell by $7.5 \%$ due to the transition to new standards for measuring fuel consumption. And many companies 


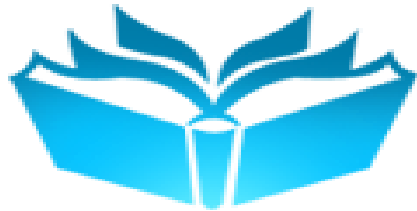 \\ I JRD ET \\ International Journal of Recent Development in Engineering and Technology \\ Website: www.ijrdet.com (ISSN 2347-6435 (Online)) Volume 10, Issue 1, June 2021) \\ Manuscript Received: 02 Feb 2021, Received in Revised Form: 18 May 2021, Accepted: 19 June 2021 DOI: 10.54380/IJRDETV10I108}

were simply not ready for such situation - sales of some versions of cars were temporarily discontinued [4].

The state policy of a number of countries also did not stand aside. It is planned, that Sweden in 2030 will stop selling cars with internal combustion engines. This is one of the key points of the program of the new government, which considers the fight against global warming and the implementation of the Paris Climate Agreement as priority steps. In order to achieve this goal, the authorities are going to work actively in the coming years to create a ramified infrastructure throughout the country for recharging electric vehicles.

Nevertheless, Sweden is already the tenth country that has announced a specific date for the termination of registration of new cars with gasoline and diesel engines. Denmark, Israel, Ireland, Iceland, the Netherlands and Paris intend to abandon internal combustion engines by 2030 . The same term is called China (the world leader in quantity of electric vehicles sold) and India. Norway plans to abandon cars with internal combustion engines in 2025 . Almost half of passenger car sales in this country came from "green" cars last year. The share of electric vehicles was $31.2 \%$, the rest were plug-in hybrids [5].

Almost half of the new cars sold in Norway today are full electric cars, and another $15 \%$ are plug-in hybrids. That is, their total share in new car sales is approaching $60 \%$ now, and it has a tendency to further increase. When buying some models, customers even have to go to the waiting list.

It should be noted that subsidies and preferences in Norway exist not only with regard to the cars themselves, but also for the infrastructure and the business involved in its creation - for example, benefits for companies that develop a network of chargers.

Electric cars are beginning to affect slowly on the structure of hydrocarbon consumption. According to Bloomberg NEF, electric cars reduced gasoline and diesel consumption in 2019 by 96 thousand barrels more per day $(15,264,000$ liters), and the total "substitution" will be 352 thousand barrels per day - about the same amount, that "burn" such countries as Peru or Portugal.

At first glance it seems that this is significant, but the growth in oil demand since 2011 has intended to 12 million barrels per day, while total consumption is 100.6 million. It turns out that the influence of electric vehicles is only $0.35 \%$ of global demand. However, absolute values are not so important, but the trend - the "substitution" in 2019 is 14 times more than in 2014.
However, electric buses (not electric cars) are considered as the main factor for such replacement. 270 thousand from 352 thousand barrels per day account for just such electric vehicles.

Analysts at Bloomberg NEF estimate that 1,000 electric buses "replace" 500 barrels per day and 1,000 electric vehicles - just 15 barrels. The reasons, of course, are in large runs and constant use of electric buses.

According to forecasts, the development of electric vehicles, supported by the governments of many states and public opinion, will lead to the fact that they will reduce consumption by 6.4 million barrels per day by 2040 . And another 7.5 million will be "reduced" by technologies that decrease fuel consumption in internal combustion engines. However, the world spends 100 million barrels daily now. So there can be no talks about complete rejection of hydrocarbons [6].

The COVID-19 pandemic also made its adjustments. Sales of EV and hybrids on the world market of electric vehicles were steadily growing $(+16 \%$ in February 2020$)$ until March 2020, despite the even then collapsed Chinese market (minus $21 \%$ in January and minus $65 \%$ in February). However, many experts in this field predict a global decrease in sales in the world in 2020 by more than $40 \%$ (from 2.2 million to just 1.3 million units). Moreover, it is believed that coronavirus will not be the only reason for such a massive decrease in sales: the ultra-low oil prices (and, accordingly, gasoline prices) and the disruption of plans for the release of new models of electric vehicles, which were scheduled for 2020 (for example, until the end of the year Volkswagen ID3 and Ford Mustang Mach-E will unlikely presented on the market) also contribute to the EV market narrowing.

There is a growing fear among many traders that in 2020 oil demand may fall to the minimum achieved during the Great Recession in 2009 or even exceed the record 2.65 million barrels recorded in 1980, when the global economy crashed after the second oil crisis.

Oil prices fell by $50 \%$ in Q1 2020, and falling oil demand leads to the deterioration in the global economy. The total global demand for oil in 2020 is expected to reach 99.73 million barrels per day. Moreover, it is predicted that oil consumption in the second half of the year will be higher than in the first half of the year. The demand for OPEC oil, according to the organization's forecasts, is expected to reach 28.2 million barrels per day in 2020, which is approximately 1.7 million barrels per day below the level of 2019 [7]. 


\section{$=$ \\ I JRD ET \\ International Journal of Recent Development in Engineering and Technology \\ Website: www.ijrdet.com (ISSN 2347-6435 (Online)) Volume 10, Issue 1, June 2021) \\ Manuscript Received: 02 Feb 2021, Received in Revised Form: 18 May 2021, Accepted: 19 June 2021 DOI: 10.54380/IJRDETV10I108}

In addition, customers who buy an electric car for the first time (and most number of these people) due to a sense of uncertainty will be wary of new technologies as well. Thus, demand for electric cars is expected to fall dramatically in the remaining months of 2020, and it is not known whether it will recover next year.

Nevertheless, for the future, experts predict a rise in the electric car segment, which, in their opinion, will begin in 2022: just when it is expected that prices for cars with ICE and EV will approximately equalize [8, 9] (Fig. 1).

As a rule, automakers correlate consumption with carbon dioxide $\left(\mathrm{CO}_{2}\right)$ emissions. European car owners, for example, are studying the data on harmful emissions when choosing a new car for their own benefit, because if a car generates $\mathrm{CO}_{2}$ less, the chance of receiving tax benefits from the government is greater.

At the same time, environmental damage is measured not only in the amount of $\mathrm{CO}_{2}$ emitted directly during the movement of the car, but also in the value of the "carbon footprint", which is understood as the totality of all the harmful emissions and greenhouse gases that an object produces during its life cycle.

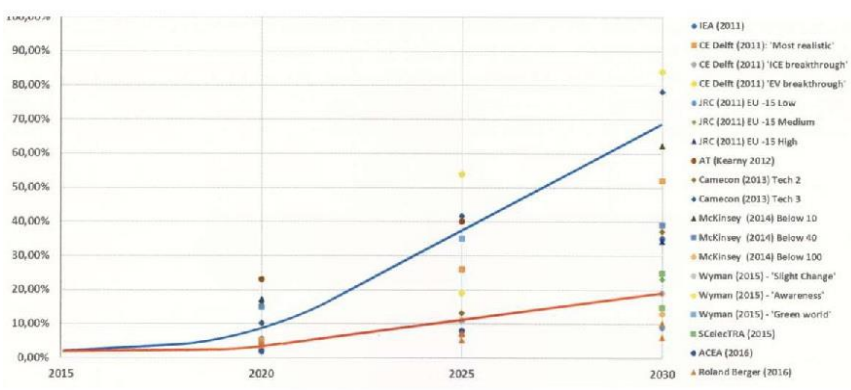

Figure 1 - Overview of recent market forecasts for Europe and market share projections for electric and plug-in vehicles (new sales). Lower curve: perseverant market scenario based on $\mathrm{CO}_{2}$ targets achieved with a focus on technology improvements and hybridization of ICE-based vehicles. Upper curve: expected development under assumption of reaching major technological breakthrouth for |EVs (Battery technology: lowering price and extended lifetime so that by 2020 medium0size PHEV become competitive in partially urban and nonurban transport, and small (urban) FEVs competitive are competitive with their ICE equivalent, resulting in a mass market uptake) [9]

In the case of a single car, the carbon footprint is not only $\mathrm{CO}_{2}$ emissions directly during the combustion of fuel, but also all environmental pollution during the production of the car.

It was found, that because of the technology of creating batteries during the production of an electric car, more greenhouse gases enter the atmosphere, than during gas emission of a car with an internal combustion engine. However, an electric car will regain this advantage of its gasoline or diesel counterparts in the future. The production of electricity that "green" vehicles consume is generally less harmful to the environment than the carbon footprint of a car with an internal combustion engine that emits $\mathrm{CO}_{2}$ into the air every day for many years [10].

In the frames of tests, Volkswagen experts compared an electric car to a diesel car. The results are impressive: during the most harmful phase - running the engine at full power - the diesel engine emits $111 \mathrm{~g}$ of $\mathrm{CO}_{2} / \mathrm{km}$.

The carbon footprint of the electric car in a comparable (maximum) phase is $62 \mathrm{~g} \mathrm{CO}_{2} / \mathrm{km}$, but this is not car emissions, but harm from the production of electricity for it. Even such a carbon footprint can be minimized by introduction of new technologies and methods for generating energy. Together with the proliferation of electric vehicles, this should significantly affect the total greenhouse gas emissions.

At the same time, according to scientists from the Munich Institute for Economic Research, cars with an electric motor in some cases emit more carbon dioxide than cars with a diesel engine. Thus, a comparative study of middle-class vehicles Tesla Model 3 and Mercedes C 220 $\mathrm{d}$, carried out by scientists from the CESifo research group at the Institute for Economic Research in Munich, showed that the first model emits more carbon dioxide into the atmosphere than the second car with a diesel engine. Despite the majority opinion that the mass introduction of electric vehicles is environmentally friendly, it turned out that the electric vehicle produces $25 \%$ more emissions than the German automaker's model. Mercedes C 220 d emits $117 \mathrm{~g}$ of carbon dioxide per $1 \mathrm{~km}$, while the electric car 159 g. The study emphasizes that the extraction and processing of lithium, necessary for the production of batteries, also requires a large amount of energy. A battery with a capacity of $75 \mathrm{kWh}$ emits from 10 to 14 thousand $\mathrm{kg}$ of carbon dioxide. According to scientists, in view of the 10 -year battery life and the average annual mileage of an electric vehicle of 15 thousand $\mathrm{km}$, for which the battery is designed, 73-98 $\mathrm{g}$ of carbon dioxide per $1 \mathrm{~km}$ corresponds to production and further processing of a battery [11].

There are countries in the world that have truly clean electricity from renewable sources. A 2020 Energy Transition Index rating indicates that green electricity is best in Sweden, which receives $74.2 \%$ of its energy from renewable sources. The United States is 32nd on this list, 


\section{U \\ International Journal of Recent Development in Engineering and Technology \\ Website: www.ijrdet.com (ISSN 2347-6435 (Online)) Volume 10, Issue 1, June 2021) \\ Manuscript Received: 02 Feb 2021, Received in Revised Form: 18 May 2021, Accepted: 19 June 2021 DOI: 10.54380/IJRDETV10I108}

and China is 78th. Russia takes 80th place, Ukraine - 102nd out of 115 countries, and Kazakhstan - $88^{\text {th }}$.

Therefore, the diesel engine definitely has a future. Experts call for transparency in terms of fuel consumption and carbon dioxide emissions by introducing new technologies that can reduce emissions to a level that is significantly lower than official restrictions introduced since 2020, and in real traffic conditions.

The future penetration of electric vehicles and hybrids on the market depends on many factors, including technological developments and breakthroughs, policy support, deployment of charging infrastructure, production capacities, future customers' needs for mobility and adoption of new technologies, as well as economic parameters such as car production cost, cost of ownership of a vehicle and energy prices. Based on the interaction of these factors, several forecasting exercises have been performed in recent years. Uncertainty in the qualifications of the above factors leads to a wide range of options [9].

It is known that the main driver of the growth of the electric vehicle fleet in any country is government subsidies and benefits, which are developed on the basis of multivariate analysis. At the same time, it seems that the development of recommendations on electromobility stimulating should be carried out not only on the basis of the assumption of a steady increase in the fleet of electric cars, but also taking into account the prevailing realities of joint existence and the related characteristics of electric cars and cars with classic internal combustion engines (diesel and gasoline), as well as wide usage of hybrid and plug-in modifications.

The solution of the problem can be performed using the game theory.

\section{State-Of-ARt Of The Game Theory Development}

At the beginning of its existence, the game theory was focused on describing various types of equilibria in the particular games of different types: the inverse reasoning method in games with sequential moves, minimax in games with zero sum involving two players, and Nash equilibrium in a more general category of games with parallel moves. All these strategies were illustrated in the context of a number of important games (prisoners' dilemma, trust game, family dispute, coward game, etc.) [12 - 14].

Thomas Schelling was the first who has developed the idea that one or both players can take actions aimed at changing the game progress - this idea has become the central theme of the whole theory of games [15]. He clearly defined what namely is necessary to ensure for the strategy was reliable. In addition, he analyzed such a delicate and risky strategy as balancing on the verge.

Reinhard Selten, who in 1994 became one of the first specialists in game theory received the Nobel Prize (along with John Nash and John Harsanyi), formulated a more precise formal definition of the concept of reliability of a strategy, namely, the concept of perfect equilibrium of a sub-game, which is a generalization of the method of inverse reasoning [16-18].

There are several ways to classify game tasks. The difference between static and dynamic games is due to the ability of players to observe each other's actions and respond to them. Players make decisions at the same time in static games, and these decisions are not subject to review. But there is a more complicated order of moves in dynamic games.

The concept of a mixed strategy is one of the often criticized places of the game-theoretic approach to the analysis of the behavior of competing actors. The doubts are expressed often that the competing actors make decisions randomly, as their decisions seem thoughtful. However, there are several reasons justifying the use of mixed strategies in modeling the behavior of the competing actors. First, there is evidence of their usage of mixed strategies. Secondly, mixed strategies can be interpreted as pure strategies in games with a large number of players. And thirdly, someone's behavior can be regarded as random when we don't have all the information about the target function of this competing actor; from his own point of view, its behavior will be determined.

In order to prove the usage of mixed strategies, based on observations of the strategies chosen by the players, but not on the decision-making mechanism, a large amount of observations is required. Moreover, it is essential that the actions of two or more players are observed in similar conditions many times in a row. For example, sports statistics is a good source of such data [19-20].

Games in which the sum of the winnings of the players is the same regardless of the type of strategies chosen by the players are an important subclass of games. Such games are often also called zero-sum games. Examples of zero- 


\section{S \\ International Journal of Recent Development in Engineering and Technology \\ Website: www.ijrdet.com (ISSN 2347-6435 (Online)) Volume 10, Issue 1, June 2021) \\ Manuscript Received: 02 Feb 2021, Received in Revised Form: 18 May 2021, Accepted: 19 June 2021 DOI: 10.54380/IJRDETV10I108}

sum games are salon games, games of the "inspection" type, election campaign (in the event that the costs of politicians do not depend on their actions), the conclusion of option contracts in the stock market. The existence of equilibrium and many other results for this class of games were obtained by John von Neumann [21].

The game theory has found its application in a number of economic problems. In the face of negative dynamics in the volume of solvent demand of consumers and the presence of a sufficient number of independent sellers on the market, characteristic of the current economic situation, competition for markets for products is becoming increasingly acute. Entrepreneurs, trying to get a one-time increase in income, often take extreme strategies among of all possible development strategies (which are not optimal in the global sense), trying to "survive", they don't think about strategic development, long-term preservation of the sales market, and they often criticized the phenomenon of "competition" [22-23].

There are cases when the desire of several firms to improve their own position in the market for the sale of goods, on the contrary, leads to a deterioration in the position of these firms, a fall in their total income (disequilibrium of J. Nash) [24]. However, competition is the only way to survive and develop, creating the conditions for improving the production of goods, introducing high technology, contributing to lower prices for the final product of production. Multiplicity of strategies of behavior of actors of competitive rivalry [2526] (conservation strategy, strategy of crowding out a competitor from the sales market of products, strategy of expanding the market by attracting new customers, etc.) are of great importance in the competition. Strengthening market position in most cases is associated with a weakening of rivals' positions.

Full crowding out of the market leads to significant losses; partial crowding out of the market is characterized by moderate dynamics of income decline. The complexity and multidimensional nature of the competition for product sales markets requires the use of the game theory. At the same time, the game-theoretic model is an option for formalizing competition [27].

After the implementation of the mathematical modeling stage for the economic situation (formalization) it is necessary to carry out a subsequent study, which consists in:

- clarification of the type of game taking into account the classification of games (for example, whether the game under consideration is a game with a zero sum);

- application of the principle of domination (majorization) of strategies that allows to reduce the dimension of the payment matrix by eliminating pre-disadvantageous strategies;

- research for the presence of equilibrium (single or multiple equilibrium, lack of equilibrium);

- usage of the apparatus of pure strategies (in the presence of equilibrium), which consists in highlighting the net maximin strategy and the net minimax strategy allowing to obtain the best guaranteed result in the worst conditions (optimization principle, J. Nash);

- application of the apparatus of mixed strategies (in the absence of equilibrium), which implies the search for a solution in the form of a mixed strategy.

Thus, the complexity of economic, political and other aspects in the implementation of electric mobility makes the application of game theory very relevant in determining the strategy for the joint operation of cars equipped with engines of various types.

\section{Application Of The Game Theory To Determine THE STRATEGY FOR THE JOINT OPERATION OF CARS EQUIPPED WITH ENGINES OF VARIOUS TYPES (ELECTRIC AND INTERNAL COMBUSTION)}

Solution of this problem can be carried out in accordance with game theory - sufficiently new, but booming part of modern mathematics. In contrast to optimization theory, studying the possibilities of the optimal solution construction for a system as a whole, game theory studies optimization methods of individual profit in competition with other persons (events), which rationally aspire to satisfaction of their own profits.

Then the gain is determined by the formula [28]

$$
R=\sum_{i, j, k, l=1}^{2} R_{i, j}^{k, l},
$$

With this formulation, a general assessment of the economic and environmental characteristics of $R_{11}, R_{12}$, $\mathrm{R}_{21}, \mathrm{R}_{22}$, determined by the technical level of the applied electric (EE), hybrid (HYB), plug-in (PLUG) and internal combustion engines (ICE) can be considered a victory in a game with a nonzero sum. 


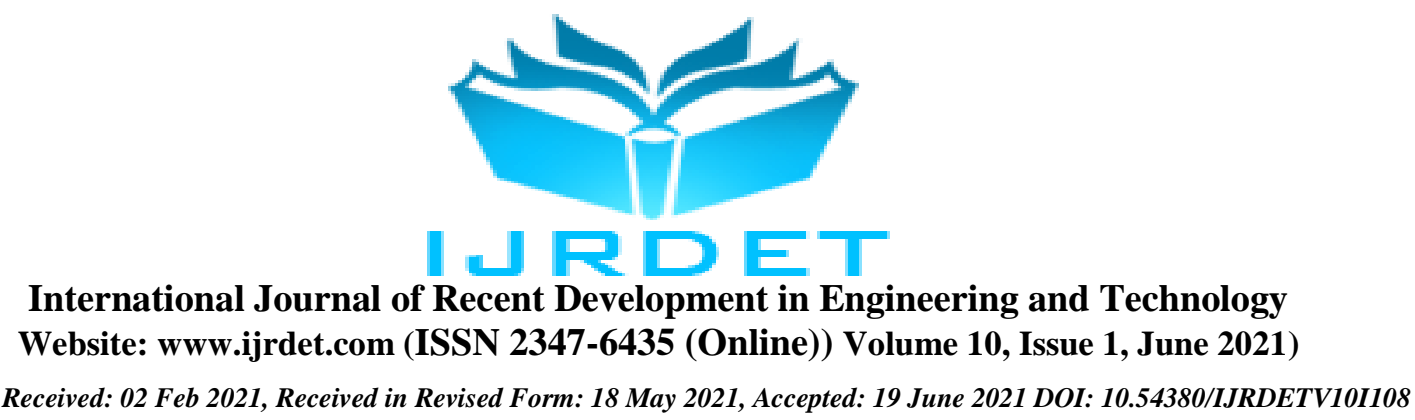

Manuscript Received: 02 Feb 2021, Received in Revised Form: 18 May 2021, Accepted: 19 June 2021 DOI: 10.54380/IJRDETV10I108

Estimation of a win (the best correlation between characteristics of applied propulsion systems) can be carried out from a point of view of minimax theory (lower limit of estimation - minimal, but guaranteed win), as well as from the point of view of construction of equilibrium solution (such strategy, according to which any attempt of any gamer to change his strategy, when his partner insist on initial choice, will not lead to increase of a win of a gamer, breaking a strategy).

For clarity, we consider only 2 engine characteristics (environmental and economic). A similar analysis can be performed for a larger number of parameters.

Let us develop a payoff matrix for this formulation. It must be mentioned, that generally speaking its coefficients depends from a moment of observation, and so it reasonable must speak about a totality of payoff matrixes.

The following notation is used in the matrix below:

$\mathrm{R}_{\mathrm{E}}^{\mathrm{ICE}}, R_{C}^{I C E}$ - environmental and economic characteristics of cars with internal combustion engines;

$\mathrm{R}_{\mathrm{E}}^{\mathrm{HYB}}, R_{C}^{H Y B}$ - environmental and economic characteristics of cars with hybrid engines;

$\mathrm{R}_{\mathrm{E}}^{\mathrm{PLUG}}, R_{C}^{\text {PLUG }} \quad$ - environmental and economic characteristics of plug-in hybrids;

$\mathrm{R}_{\mathrm{E}}^{\mathrm{EE}}, R_{C}^{E E}$ - environmental and economic characteristics of electric vehicles.

\section{Economy}

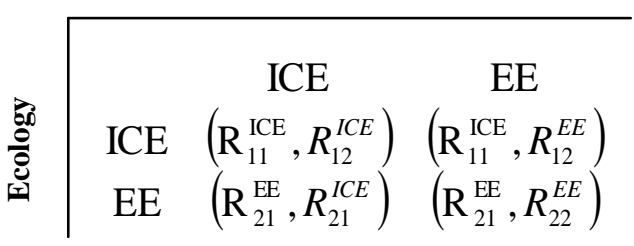

Analysis of such payoff matrix is carried out using known methods. Preferences of gamers are usually indicated by arrows (direction corresponds to larger win). Equilibrium point is defined as a point to which vertical arrows (the first gamer preference of the first strategy owing to connected with it larger win) indicate, as well as horizontal one (preferences of the second gamer).

It is evident, that in accordance with such formulation one can find equilibrium point $(A, B)$ by:

$$
\begin{aligned}
& A=\max _{i}\left\{R_{(i . j)}^{(j)}\right\}, \\
& B=\min _{j}\left\{R_{(i, j)}^{(i)}\right\}, \quad i, j=\overline{1,2 .}
\end{aligned}
$$

Guaranteed level and maximin strategies can be defined on lack of knowledge about actions of other gamer. However basing on the proposed method of payoff matrix construction, one can obtain, that the results of maximin theory application are identical to the equilibrium point.

The question remains open, in which sense a win and corresponding to it strategy is the best. It is considered, that a gamer guarantees to himself maximin (and possibly, the largest) win, using the equilibrium strategy [28].

After definition of equilibrium strategy (and so to the maximum guaranteed win, describing the optimal correlation between expert marks of EE, hybrid models, plug-in cars and ICE), the conclusion about the most effective strategy for their joint application can be made. In such a way, the most effective direction of investigations for increasing of effectiveness of developed policies and strategies can be proposed.

\section{Example 1}

Let us consider the case when cars with different engines (ICE, hybrid, plug-in hybrids and electric cars) are used in the region. At the same time, emissions of harmful substances produced by machines equipped with these engines (taking into account their quantity and the carbon footprint of electric vehicles) are shown in Table 1.

Then expert estimates of the engines used can be determined by the following procedure.

Let us assume that with a maximum expert environmental rating of 100 (for a perfectly environmentally friendly engine), and estimates for real ICE engines, hybrids, plug-in hybrids and EE (taking into account the carbon footprint) are distributed according to the data shown in table 1 (expert estimates of cost are also given here).

The payment matrix will take the following form for this case:

\section{Economy}

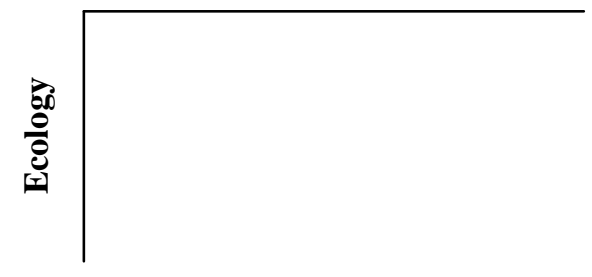




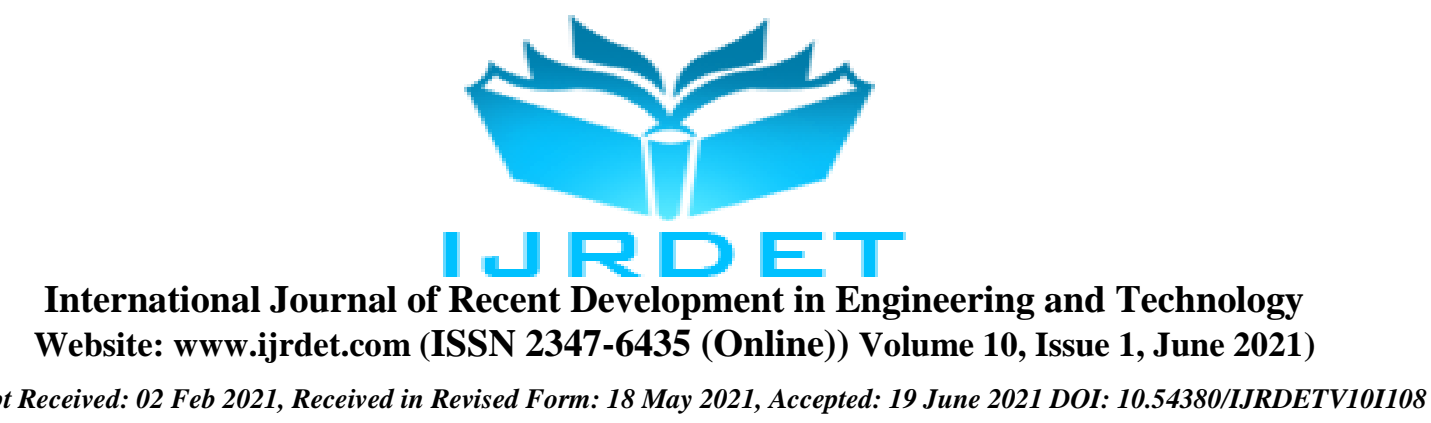

Manuscript Received: 02 Feb 2021, Received in Revised Form: 18 May 2021, Accepted: 19 June 2021 DOI: 10.54380/IJRDETVI0I108

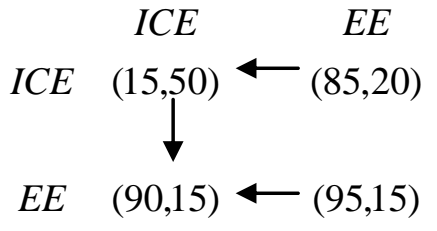

TABLE I

EXPERT ASSESSMENTS FOR CARS, OPERATING IN THE REGION

\begin{tabular}{|c|c|c|c|c|c|c|}
\hline № & Type & 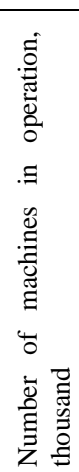 & 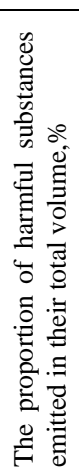 & 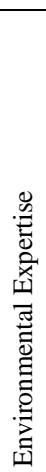 & 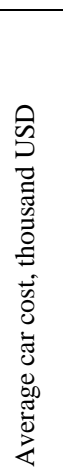 & 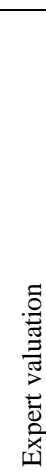 \\
\hline 1 & ICE & 75,0 & 85 & 15 & 10,0 & 50 \\
\hline 2 & Hybrid & 15,0 & 6 & 85 & 18,0 & 20 \\
\hline 3 & Plug-in & 5,0 & 5 & 90 & 22,0 & 15 \\
\hline 4 & $\mathrm{EE}$ & 5,0 & 4 & 95 & 28,0 & 15 \\
\hline
\end{tabular}

It is obviously, that the solution can be based on pure strategies. For the matrix under consideration, there is a saddle point - $(90,15)$. Thus, the gain corresponds to the environmental and cost characteristics of plug-in hybrids, which are preferred for operation in this region.

\section{Example 2}

Let us consider the case when it is predicted that by 2030 only electric cars, hybrids and plug-in hybrids will be mainly used in the region. In this case, expert assessments of the used EE, hybrids, plug-in hybrids and ICE are distributed according to the data indicated in table 2 .

The payment matrix will take the form for this case:

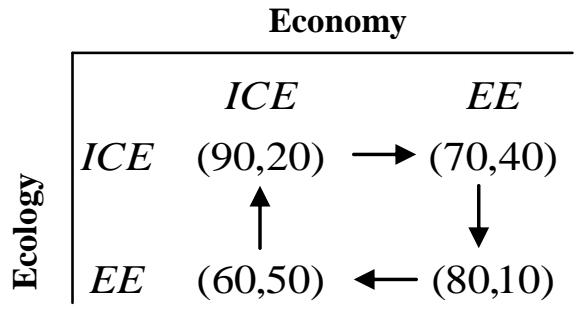

It is evident, that solution in pure strategies for this matrix does not exist. Let us find this solution in mixed strategies. In order to guarantee equal (or sufficiently close) value of characteristics for ICE (gamer 1) out of dependence of characteristics for $\mathrm{EE}$ (gamer 2), let concentrate our attention on the ecological characteristics, and so we'll calculate mixed strategies, determined for economic ones.

In compliance with game theory terminology, if gamer 2 choose the first column of a payoff matrix with probability $\mathrm{q}$ and the second column - with the probability 1-q, then the expectation value for both rows of payoff matrix of a gamer 1 must be equal, that is:

$$
90 * q+70 *(1-q)=60 * q+80 *(1-q) .
$$

Consequently, $q=1 / 4,1-q=3 / 4$.

Thus gamer 1 must choose the first column of the payoff matrix with probability $1 / 4$ and the second column - with probability 3/4. At that anticipated payoff of gamer 1 will be equal to 75. As is easy to see, that this value of anticipated payoff will be saved when gamer 1 uses any mixed strategy $(p, 1-p)$, since

$90 * p * 1 / 4+70 * p * 3 / 4+60 *(1-p) * 1 / 4+80 *(1-p) * 3 / 4=75$.

Consequently, $q=1 / 4,1-q=3 / 4$.

Thus gamer 1 must choose the first column of the payoff matrix with probability $1 / 4$ and the second column - with probability $3 / 4$. At that anticipated payoff of gamer 1 will be equal to 75 . As is easy to see, that this value of anticipated payoff will be saved when gamer 1 uses any mixed strategy $(p, 1-p)$, since

$$
\begin{gathered}
90 * p * 1 / 4+70 * p * 3 / 4+60 *(1-p) * 1 / 4+80 *(1-p) * 3 / 4=75 . \\
\text { TABLE II }
\end{gathered}
$$

EXPERT ASSESSMENTS FOR CARS, OPERATING IN THE REGION 


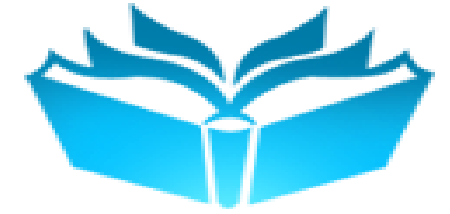 \\ URDET}

International Journal of Recent Development in Engineering and Technology

Website: www.ijrdet.com (ISSN 2347-6435 (Online)) Volume 10, Issue 1, June 2021)

Manuscript Received: 02 Feb 2021, Received in Revised Form: 18 May 2021, Accepted: 19 June 2021 DOI: 10.54380/IJRDETV10I108

\begin{tabular}{|c|c|c|c|c|c|c|}
\hline № & Type & 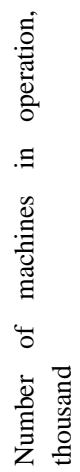 & 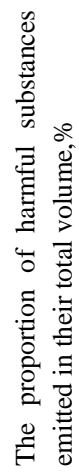 & 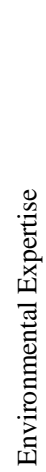 & 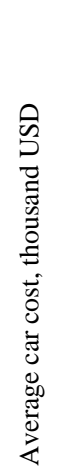 & 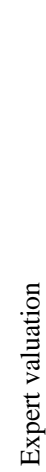 \\
\hline 1 & ICE & 10,0 & 10 & 90 & 30,0 & 20 \\
\hline 2 & Hybrid & 30,0 & 30 & 70 & 18,0 & 40 \\
\hline 3 & Plug-in & 60,0 & 40 & 60 & 15,0 & 50 \\
\hline 4 & $\mathrm{EE}$ & 30,0 & 20 & 80 & 40,0 & 10 \\
\hline
\end{tabular}

Just as gamer 1, desiring to obtain, that the anticipated payoff of a gamer 2 does not depend of choosing by him mixed strategy, with the help of payoff matrix of gamer 2 writes:

$$
20 * p+50 *(1-p)=40 * p+10(1-p) .
$$

Hence, $p=2 / 3,1-p=1 / 3$.

Then mixed strategy is of the form: $\left(\mathrm{s}_{1}, \mathrm{~s}_{2}\right)=\left(2 / 3^{*} A_{1}+\right.$ $\left.1 / 3^{*} A_{2}\right)+\left(3 / 5^{*} B_{1}++2 / 5^{*} B_{2}\right)$, and equilibrium gain $(A, B)$ $=(75,30)$.

This means that at the point in operation under consideration, environmental characteristics can be estimated at 75 points, and economic characteristics - at 30 points (taking into account the error in evaluating in the expert method). Therefore, for this region it is advisable to focus on the introduction of namely electric vehicles and hybrid cars.

It should be noted that when constructing forecast estimates, it is advisable to expand the analysis by considering various forecast parameters (both quantitative and cost). Of considerable interest may also be a long-term analysis based on the forecast of used cars.

The developed approach, based on the application of game theory, allows to analyze not only the current market for used cars, but also to outline the level of strategic measures aimed at attracting users to a particular market segment.

\section{CONCLUSION}

The shortage of fuel and the associated increase in energy prices, as well as a worldwide understanding of the need to protect the environment, are causing more and more car manufacturers to look for an alternative to an internal combustion engine.

At the moment, electric cars are the best type of passenger transport for the urban cycle that meets all the requirements of environmental and energy safety. The main advantage of electric vehicles is a high engine efficiency (76\% versus $25-30 \%$ for ICE). This is achieved due to the simplicity of the engine design, which ensures high reliability.

But for the widespread introduction of electromobility, financial preferences are needed. Looking realistically, electric mobility is developing in those countries where there is strong financial support: subsidies or tax exemptions, free parking, free travel on toll roads for electric cars, etc.

But the internal combustion engines definitely has a future, especially, in hybrid versions. Experts call for transparency in terms of fuel consumption and carbon dioxide emissions by introducing a new technologies that can reduce emissions to a level that is significantly lower than official restrictions introduced since 2020, and in real traffic conditions. Moreover, development of new technologies makes technical characteristics of diesel engines sufficiently close to the electric ones.

So it seems that the development of recommendations and policies should be carried out not only on the basis of the assumption of a steady increase in the fleet of electric cars, but also taking into account the prevailing realities of joint existence and the related characteristics of electric cars and cars with classic internal combustion engines (diesel and gasoline), as well as hybrid modifications.

\section{REFERENCES}

[1] Haidukevich D., 2019. A complete ban on gasoline cars: the probability is very high.AUTO.MAIL.RU [Internet]. Cited 2019 May 16. Available from: https://auto.mail.ru/article/72790kogda_zapretyat_benzinovye_mashiny_i_pochemu/?fromemail/ .

[2] AUTO.TUT.BY [Internet], 2019. Volkswagen will launch 70 new electric vehicles on the market in the next 10 years; cited 2019 March $12 . \quad$ Available from: https://auto.tut.by/news/autonews/629554.html/ .

[3] AUTO.MAIL.RU [Internet], 2019. One more automaker will leave Europeans without a "diesel"; cited 2019 September 24. Available from: https://auto.mail.ru/article/74499. 


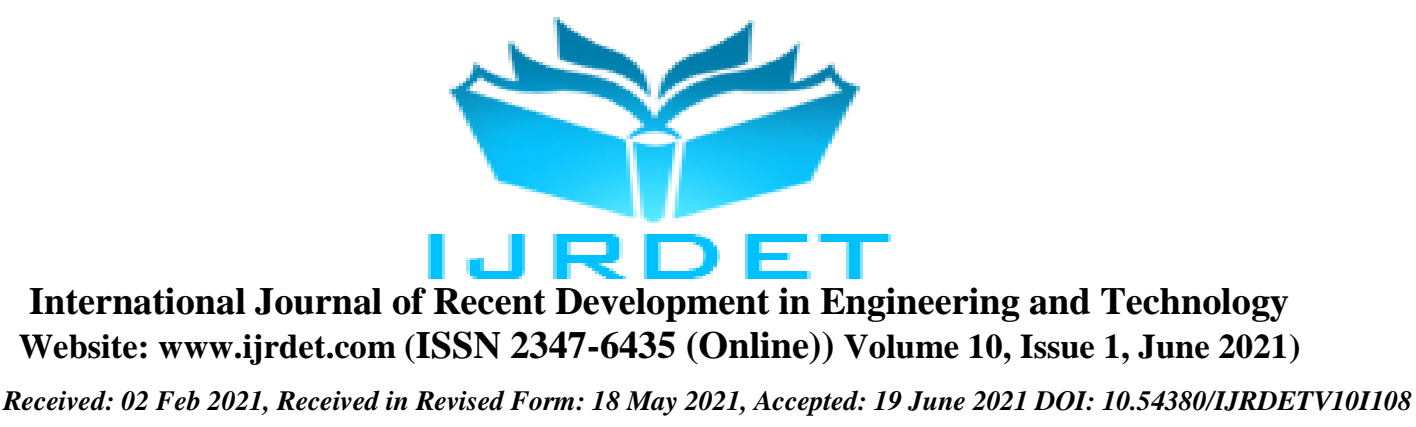

Manuscript Received: 02 Feb 2021, Received in Revised Form: 18 May 2021, Accepted: 19 June 2021 DOI: 10.54380/IJRDETV10I108

eshche_odin_avtoproizvoditel_ostavit_evropeicev_bez_dizelya/?fro memail .

[4] Haidukevich D., 2019. The accident of the diesel engine and the victory of "Jeeps": studying the European market. AUTO.MAIL.RU [Internet]. Cited 2019 December 31. Available from: https://auto.mail.ru/article/71583-

katastrofa_dizelya_i_pobeda_dzhipov_izuchaem_rynok_evropy/?fro memail/ .

[5] AUTO.MAIL.RU [Internet], 2019. One more country will ban gasoline and diesel cars; cited 2019 January 24. Available from: https://auto.mail.ru/article/71503-

eshche_odna_strana_zapretit_benzinovye_i_dizelnye_avto/?fromem ail/

[6] Gagarin V., 2019. Electric cars against oil. Who will win? AUTO.MAIL.RU [Internet]. Cited 2019 March 27. Available from: https://auto.mail.ru/article/72272-

elektromobili_protiv_nefti_kto_pobedit/?fromemail/.

[7] VESTI.RU [Internet], 2020. Oil consumption in the world is approaching a record drop; cited 2020 March 16. Available from: https://www.vesti.ru/doc.html?id=3248510 .

[8] DROM [Internet], 2020. Car market -2019 and prognoses for 2020; cited 2020 May 02. Available from: www.drom.ru/info/misc/78049.html.

[9] ERTRAC, 2017. European Roadmap Electrification of Road Transport. ERTRAC; 2017.

[10] AUTO.MAIL.RU [Internet], 2019. How do cars really spoil the environment and what to do about it? Cited 2019 November 05. Available from: https://auto.mail.ru/article/74695kak_na_samom_dele_mashiny_portyat_ekologiyu_i_chto_s_etim_d elat/?fromemail/ .

[11] World Economic Forum [Internet], 2020. Energy Transition Index 2020: from crisis to rebound; cited 2020 May 13. Available from: https://www.weforum.org/reports/fostering-effective-energytransition-2020.

[12] Owen G., 2014. Game theory. Moscow (Russia): LKI.

[13] Vlasov D., 2016. A retrospective analysis of the development of methods and models of game theory. Innovation Science; 8-1: 42-43.

[14] Füllbrunn S., 2007. Collusion or sniping in simultaneous ascending auctions a prisoner's dilemma. Int. Game Theory Rev. [Internet]. Cited 2007 February; 13(01):75-82. Available from World Scientific Publishing.

[15] Schelling T., 2007. The Strategy of Conflict. Moscow (Russia): IRICEN.

[16] Selten R., Harsanyi J., 1992. System Builder and Conceptual Innovator', Games and Economic Behavior. Berlin (Germany): Springer-Verlag.

[17] Nash J., 1950. The Bargaining Problem. Econometrica. 18: 155162.

[18] Binmore K., Rubinstein A., Wolinsky A., 1986. The Nash Bargaining Solution in Economic Modelling . RAND Journal of Economics. 17: 176-188.
[19] Coriolis G., 2015. The mathematical theory of the phenomena of billiard games. Moscow (Russia): LIBROCOM.

[20] Krasnov M., 2017. Higher mathematics as a whole. Volume 5: Probability Theory, Mathematical Statistics, Game Theory. Moscow (Russia):GOSTECHIZDAT.

[21] Nash J., 2008. The agencies method for modeling coalitions and cooperation in games. Int. Game Theory Rev. [Internet]. Cited 2008 December; 10(04):539-564. Available from World Scientific Publishing.

[22] Vlasov D., 2016. Methodological aspects of decision making. Young scientist. 4: 760-763.

[23] Vlasov D., 2016. Game-theoretic model of competition for product markets. Economics and Management Issues. 5 (7): 27-29.

[24] Morgenstern O., Neumann J., 2012. Game Theory and Economic Behavior. Moscow (Russia): Book on Demand.

[25] Moreno-Ternero J., 2007. Bankruptcy rules and coalitional manipulation. Int. Game Theory Rev. [Internet]. Cited 2007 February; 09(01):105-118. Available from World Scientific Publishing.

[26] Cabo F., Martin-Herran G., Martinez-Garcia M., 2008. Technological leadership and sustainable growth in a bilateral trade model. Int. Game Theory Rev. [Internet]. Cited 2008 March; 10(01):73-100. Available from World Scientific Publishing.

[27] Porter M., 2011. Competitive Strategy. Methodology for analyzing competitor industries. Moscow (Russia): Alpina Publisher.

[28] Saati, T.L., 1977. Mathematical models of conflict situations. Moscow (Russia): Soviet radio. 